\title{
PRESENTACIÓN: DIALOGOS ENTRE LA HISTORIOGRAFÍA Y OTROS SABERES EN EL MUNDO CONTEMPORÁNEO
}

Francisca Durán, Pedro Huerta, Juan Radic (editores)

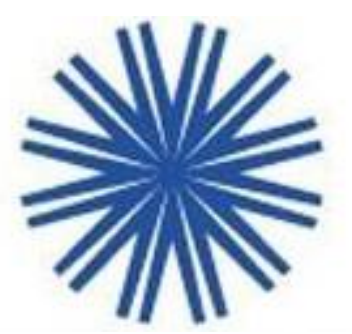

Asumiendo que el diálogo con las humanidades, las ciencias sociales y las artes es inherente al conocimiento histórico y al ejercicio historiográfico, el Número 25 de la Revista de la Academia reúne un dossier con seis artículos cuyo aporte es la reflexión en torno a la relación entre teoría, historia e historiografía y la relación con otros saberes desde la complejidad y desafíos que constituye la y de nuestra propia contemporaneidad. La fugacidad de los acontecimientos y la dispersión de los fenómenos socioculturales y políticos que marcan al tiempo presente, han trastocado las propias nociones de espacio y tiempo convirtiéndose en un auténtico reto para su conocimiento y problematización.

El propósito que motivó este número fue revisitar una antigua discusión -y tensión- en el campo de la historia, la cual se vincula al carácter difuso de las fronteras que delimitan a la disciplina histórica. Podemos decir que, desde la conformación de las disciplinas y ciencias modernas, la historia se ha situado en un terreno fronterizo que, a momentos, se ha desplazado a definiciones de método más rígidas y, en otros, se han interpelado precisamente las premisas que contienen dichos criterios, desdibujando, de esta manera, la noción de una disciplina con límites claros y fijos. El carácter inquieto de la historia ha conducido, parafraseando a la historiadora francesa Arlette Farge, a crear nuevos "lugares para la historia" y campos de lo posible. Ciertamente el diálogo y trabajo conjunto con otros saberes ha colaborado en la emergencia de una multiplicidad de caminos que se ofrecen a las/los historiadoras/es.

La historiografía constantemente interpelada por esa condición intersticial, entre la temporalidad de un pasado que intenta ser revelado y la producción de su escritura desde el presente, es una dialéctica sin resolver y propia del oficio del historiador/a. Como efecto de esa condición, la historiografía siempre ha 
buscado abrir los horizontes de interpretación y compresión en diálogo con los saberes de las humanidades y las ciencias sociales. En esa línea argumental se inscriben las contribuciones de este dossier.

Las y los autoras/es constituyen un grupo diverso de investigadoras/es que fueron convocados a reflexionar acerca de las formas -teóricas y prácticas- en que se aproximan a sus problemas de estudio, y los modos en que dialogan o entran en tensión con otros saberes del conocimiento. Las y los autoras/es en su mayoría han sido formados en el campo de la historia, sin embargo, sus artículos expresan una búsqueda más allá de lo estrictamente disciplinar, generando cruces con la filosofía, los estudios de la memoria, los estudios de la imagen, el campo de los afectos, entre otros, así como instalan una reflexión acuciosa de las nociones de interdisciplinariedad y transdisciplinariedad.

En el artículo La hermenéutica de Gadamer como fundamento teórico-filosófico de la historia conceptual en Reinhart Koselleck de David Petit, se destaca las aportaciones del filósofo alemán Hans-Georg Gadamer en relación a la perspectiva de la historia conceptual propuesta por Reinhart Koselleck. De este análisis, se desprenden, a nuestro juicio, tres cuestiones significativas ligadas al conocimiento histórico. La primera es que no se puede hacer historia sin teoría; segundo, que la historia es siempre un dialogo permanente con el saber "humano" general; y tercero, que la historia es al final del día una "hermenéutica", en tanto condición ontológica de la historicidad del ser en el lenguaje. Una hermenéutica (la historiografía) en tanto se mueve en la esfera del lenguaje y de la compresión de sentido, que como bien lo evidencia el autor "no es solo un saber teórico, sino que se convierte en una praxis".

A partir de las contribuciones de Petit, podemos conjeturar que el trabajo historiográfico, en tanto hermenéutica, funge los horizontes de sentido que se canalizan por medio del lenguaje. Lenguaje que es revelado para el/la historiador/a en una experiencia de mundo previo que es la condición de las fuentes, las que se instalan en nuestra propia condición ontológica de ser histórico. Esta es una de las principales aportaciones de Petit en relación a Gadamer, al señalar el camino de la dinámica de la compresión histórica radicada en la condición ontológica del ser histórico como lenguaje y de la historia como fusión de horizontes de experiencias de vida, que se reactualizan constantemente en el círculo hermenéutico que se genera a partir de la labor historiográfica. 
El artículo de Francisca Alarcón titulado Del Monumento al instante cualquiera: Apuntes sobre la relación entre Historiografía y lo moviente en el s. XX, se despliega un tema complejo relacionado a la capacidad de la historiografía para aprehender las nuevas formas de comunicación simultáneas. Esto implicaría romper las convenciones metodológicas y narrativas del oficio historiográfico, instalando en el/la historiador/a una preocupación por los flujos más que por los objetos concretos, es decir, una historia como devenir y heterogeneidad que se opone al modelo de lo idéntico, constante o simétrico, desde donde la historiografía pueda superar las letras como vehículo comunicativo instalándose en el terreno de la imagen-movimiento, transformando a la historiografía en una ciencia nómade en lenguaje de Deleuze citado por Alarcón.

Dentro de esta misma inquietud, se encuentra el artículo de Pedro Huerta Cazadores de huellas indíciales del estar siendo (abierto). El caso de las economías amalgamadas de Karl Polanyi. En una etapa de configuración de una caja de herramientas a partir de autores llamados por Huerta como "Cazadores de huellas indíciales", pues intentaron aprehender el acontecer de lo "social" en la perspectiva del movimiento y del continuo "arte de hacer", en palabras de Michel de Certeau citado por Huerta. Para el autor esto se relaciona con una cuestión más general que se conecta con el desarrollo de la "transdisciplinariedad", es decir, una práctica científica nómada que se ubica en "medio de" o "más allá $d e "$ las disciplinas, no como una superación sino como una constatación del acontecer que nos hace ser cada vez menos disciplinarios.

Preocupada por las formas, contenidos y estrategias metodológicas con que la historiografía afronta la dificultad que plantean para su oficio los pasados difíciles que marcaron la historia reciente de América Latina, Romané Landaeta en Historia y memoria: debates y tensiones en el siglo XXI, se aproxima a las reflexiones, problemáticas y desafíos que vislumbra la Historia del Tiempo Presente, de manera de identificar las formas en que las sociedades latinoamericanas han afrontado las herencias de los pasados autoritarios pero, por sobre todo, rastrear las reflexiones posibles que discurren en el quehacer historiográfico acerca de cómo abordar estos "pasados vivos" - como los conceptualiza Perotin Dumon, con toda la complejidad que conllevan. Con este objetivo, la autora nos introduce en los debates y propuestas que esta vertiente del saber historiográfico ha venido realizando en las últimas décadas. 
En este contexto, Landaeta deja entrever que la labor del historiador/a y su disposición para dialogar con otras disciplinas se torna fundamental para ampliar la mirada acerca de las realidades sociales a las que nos convoca el mundo actual. Sosteniéndose en un diálogo permanente con la filosofía para reflexionar acerca del modo de entender la temporalidad - el tiempo histórico - y de otros saberes como la sociología, la antropología y la psicología, entre otros, nos invita a aproximarnos desde una mirada diversa a comprender cómo se han ido desplegando las disputas por las memorias, los forzados olvidos y los sentidos sociales dado al pasado reciente, por los distintos grupos que conforman a las sociedades latinoamericanas. Es necesario entonces -señala Landaeta - un enfoque polisémico para afrontar las dificultades que representan los pasados construidos desde la subjetividad de la memoria o desde el horizonte de expectativas que vislumbra la representación que las y los sujetos realizan desde sus propias experiencias; se requiere, en definitiva, de soportes teóricos heterodoxos -eclécticos- donde la filosofía, las ciencias sociales y las humanidades, en general, asumen un papel fundamental en este repensar metodológico del oficio del historiador/a.

En esa misma dirección, discurre el artículo La repartición de los afectos. Escenas de consenso y disenso en el Chile de la transición de Cynthia Shuffer. Situado en el Chile de la transición, la autora se interroga acerca de los modos en que el poder posdictatorial - continuador del modelo establecido en dictadurabuscó establecer un orden político y cultural específico que sirviera para reconfigurar el entramado social de la naciente democracia a través de lo que denomina la "repartición de los afectos". Para ello, señala, el Estado se abasteció de un conjunto de elementos materiales e inmateriales que organizaron las prácticas de la vida social, instaurando un sentimiento de pertenencia en la comunidad, materializada en "una memoria colectiva unívoca y un conjunto de valores y normas compartidas por los sujetos", de manera de, a través de esta estructura de sentidos, organizar las prácticas y los sentidos de pertenencias de los ciudadanos. Estos artefactos, que la autora establece como constructos emocionales materializados en la idea de consenso y moderación, permitieron urdir un "peligroso dispositivo" que alineó conductas, prácticas y afectos que trazaron un modo hegemónico de memoria sobre el pasado reciente del país, relacionada especialmente al conflictivo papel jugado por las FF.AA. en la sistemática violación de Derechos Humanos. Este auténtico modo de control, concluye, ha venido a ser cuestionado sólo en los últimos años, con la emergencia de nuevas generaciones que han logrado visibilizar el disentimiento hacia esos afectos e imaginarios impuestos por la transición. 
Po último, Aldo Ahumada en Normalización Filosófica: entre filosofía y cultura, indaga acerca de los límites y fronteras que la filosofía latinoamericana fue trazando, desde los albores del siglo XX, en su constitución como disciplina "profesional e independiente". En ese orden, nos invita a analizar el pensamiento y obra de Francisco Romero -y su concepto de normalización-, para observar el modo en que se fueron fijando y estableciendo progresivamente los modos y términos específicos de lo que fue o debía ser la filosofía - una auténtica conciencia filosófica, reseña el autor-, insertando a la disciplina como saber en el campo más amplio de la cultura latinoamericana, sus imaginarios y representaciones, siendo éstas fundamentales para la constitución de un auténtico quehacer filosófico que caracteriza a la disciplina y la distingue de otros saberes. 